\title{
Prospection of Hepatitis E virus in human, swine and sewage samples in Spain
}

\begin{abstract}
Hepatitis E virus (HEV) has been detected in Spain among patients with acute hepatitis, swine livestock, wild fauna and urban sewage, but prospective studies have been scarce. The incidence of the infection among humans and the mechanisms for acquisition of local HEV strains are unknown. Serum samples from 46 prospectively selected patients displaying liver alterations were tested for IgG and IgM antibody to HEV (anti-HEV) and for HEV RNA. HEV RNA was investigated in 287 stool samples from piglets and in 45 sewage samples from a single region, and anti-HEV was tested in 94 serum samples from piglets from the same farms. Acute HEV infection was identified in six patients (13.4\%), and evidence of contact with HEV in the past, but unrelated to the ongoing liver alterations, was obtained in eight (17.3\%). Two imported and four autochthonous cases of acute infection were recorded. Most autochthonous cases were found in the Basque Country, where swine livestock is not of economic importance. HEV RNA was detected in stool samples from three piglets aged 6-8 weeks from a single farm (1\%), and anti-HEV was found among piglets from all farms at rates ranging overall from 18.1 to $58.3 \%$, but from 70.8 to $71.4 \%$ among the oldest ones (22-23 weeks old). All sewage samples tested negative for HEV RNA. The results show that locally acquired, human HEV infection might be significantly more frequent in the Northern regions of Spain, and that swine livestock might not be in the origin of most of these infections.
\end{abstract}

Keywords: HEV RNA,anti-HEV, swine livestock, urban sewage
Volume 5 Issue 5 - 2017

Fogeda M, I Avellon A,' Cabrerizo M,' Trallero G,' Garcia L, ${ }^{2}$ Martin M, ${ }^{3}$ Sampedro $A,{ }^{4}$ Sanchez $R,{ }^{5}$ Schuller de Santos $C,{ }^{2}$ Serrano E, ${ }^{6}$ Cilla CG, ${ }^{6}$ Garcia Arevalo C, ${ }^{6}$ Tajada P,' Echevarria JM'

'Department of Virology, Nacional Centre for Microbiology Instituto de Salud Carlos III, Spain

${ }^{2}$ Department of Virology, Nacional Centre for Microbiology Consorcio Agropecuario, Spain

${ }^{3}$ Department of Anatomia Animals, Campus Bellaterra, Spain ${ }^{4}$ Department of Anatomia Animals, Hospital Virgen de las Nieves, Spain

${ }^{5}$ Department of Anatomia Animals, Hospital Comarcal de Llerena, Spain

${ }^{6}$ Department of Anatomia Animals, Hospital de Donostia, Spain 'Department of Anatomia Animals, Hospital General de Segovia, Spain

Correspondence: Marta Fogeda M, Service of Diagnostic Microbiology, National Centre for Microbiology, Crta Majadahonda Pozuelo, 28220 Majadahonda, Madrid, Spain \& WERFEN, Private Company, Tel 6364065I3, Fax 34 9l 763990I, Email martafogeda@excite.com

Received: July II, 2017| Published: August 18, 2017
Abbreviations: HEV, hepatitis E Virus; EILSA, enzymelinked immunosorbent assay

\section{Introduction}

Hepatitis E virus (HEV) infection among humans is sporadic in European countries. Nevertheless, cases of HEV infection, either imported or autochthonous, have been reported from many countries, including Spain. ${ }^{1,2}$ With a single exception, ${ }^{3}$ autochthonous cases reported from Europe were always due to HEV genotype 3 (HEV-3), which has been found also in swine livestock, wild boar and deer, and might be circulating among other animals. HEV genotype 1 (HEV1) has been, however, repeatedly detected in sewage from the city of Barcelona. ${ }^{4}$ Direct contact with infected animals and consumption of contaminated meat are involved in transmission of HEV-3 to humans, ${ }^{5-7}$ but other mechanisms cannot be ruled-out. HEV-3 strains isolated from humans and swine livestock from the same country have always been found closely related. ${ }^{8,9}$

The prevalence of antibody to HEV (anti-HEV) among pigs seems quite variable in Europe, the figures ranging from $22 \%$ to $55 \%$, $^{7,10-}$ ${ }^{12}$ Spain is the second country of the European Union in regard to porcine production, and the prevalence of anti-HEV can be as high as $97 \%$ among pigs older than six months. ${ }^{10,13}$ Although this infection is often qualified as emerging in Europe, HEV has been present in Spanish pig farms at least since $1985 .{ }^{14}$

Acute HEV infection may be entirely asymptomatic or may present as a self-limited febrile illness with abnormalities in liver function.
Mortality is low unless among pregnant women. Chronic hepatitis associated to viral persistence has, however, been reported among transplant recipients who became infected shortly after transplant. ${ }^{15,18}$ In Spain, HEV was found involved in $11 \%$ of cases from a series of acute hepatitis of unknown origin reported recently, and in $8 \%$ of those unrelated to international travel or immigration. ${ }^{2}$ In addition, the overall prevalence of anti-HEV found in samples representative of the Spanish general population ranged from 1 to $7 \%$ in studies performed in Madrid ${ }^{19}$ and Catalonia, ${ }^{20}$ respectively.

Investigation of the HEV infection has been performed mainly among patients with acute hepatitis, and this strategy cannot detect asymptomatic infections. In addition, prospective investigation of HEV among patients and swine livestock from a given geographical area has been performed just once in Spain.$^{21}$. In the present study, HEV was prospectively investigated in patients from four regions of the country who displayed either acute hepatitis or abnormal aminotransferase serum levels in absence of symptoms, and also in swine livestock and in sewage samples from one of these regions.

\section{Material and methods}

\section{Patients and clinical samples}

Prospection of human HEV infections was performed on patients admitted from January 2009 to December 2010 in four hospitals emplaced in the North (Donostia, Basque Country), the West (Llerena, Extremadura), the Centre (Segovia, Castile-León) and the South (Granada, Andalousia) of Spain. One thousand an ninety three 
patients displaying abnormal serum aminotransferase levels (ALT and/or AST $\geq 200$ ) in absence of specific markers of acute infection by hepatitis A, B and C viruses and lacking any other explanation for biochemical alterations, were selected at two local hospitals (Segovia and Llerena). In addition, 762 patients presenting with symptoms of acute hepatitis (fever, jaundice and ALT/AST $\geq 200$ ) of unknown origin were selected at two reference hospitals (Donostia and Granada). A single serum sample $(0.3 \mathrm{ml})$ was collected from all patients, and demographic, clinical and epidemiological data were recorded according to a common protocol formerly agreed by participants. Data collection included antecedents of recent travel to HEV endemic areas, frequent contact with pigs or other livestock, professional farming activity, and habits of consumption of undercooked pork meat.

Testing of human and animal samples was done after obtaining institutional approval for ethical issues.

\section{Definitions for HEV infection and disease}

Diagnosis of HEV infection and disease was based on the following definitions:

Lack of prior contact with HEV: Absence of anti-HEV IgG, IgM and viral RNA. Past infection: Presence of anti-HEV IgG in absence of anti-HEV IgM and HEV RNA. Acute infection (window period): Detection of viral RNA in absence of anti-HEV IgM and IgG. Acute infection (early seroconversion phase): Detection of anti-HEV IgM and viral RNA in absence of anti-HEV IgG. Acute infection (early post-seroconversion phase): Detection of anti-HEV $\operatorname{IgM}$ and $\operatorname{IgG}$ and viral RNA. Acute infection: (late post-seroconversion phase): Detection of anti-HEV IgM and IgG in absence of viral RNA. Any other pattern of specific markers of HEV infection was interpreted as reflecting non-specific reactivity or sample contamination. Hepatitis E: Abnormal ALT/AST serum level associated to acute HEV infection. Acute hepatitis E. Acute hepatitis associated to acute HEV infection.

\section{Samples from swine livestock}

Anti-HEV IgG and HEV RNA were investigated in serum or stool samples, respectively, from pigs grown in four farms from two localities (Cantalejo and Coca) of the province of Segovia. Twohundred and eighty-seven stool samples and 94 serum samples were obtained from individuals aged 6 to 23 weeks, from March 2009 to February 2010 (Table 1). The number of animals sampled at each farm was in proportion to the size of the herds. Individually wrapped, sterile disposable material was used for collecting the stool specimens. Samples were stored at $-80^{\circ} \mathrm{C}$ until testing.

Table I Results obtained from anti-HEV and HEV RNA testing in 46 selected patients displaying alteration of the liver function (ALT)

\begin{tabular}{|c|c|c|c|c|c|c|}
\hline \multirow{2}{*}{ Region } & \multirow{2}{*}{$\begin{array}{l}\text { Patients } \\
\text { included }\end{array}$} & \multirow{2}{*}{$\begin{array}{l}\text { Patients selected } \\
\text { for HEV testing }\end{array}$} & \multicolumn{3}{|l|}{ Anti-HEV } & \multirow{2}{*}{$\begin{array}{l}\text { HEV } \\
\text { RNA }\end{array}$} \\
\hline & & & Total (EIA) & IgG (RIBT) & $\operatorname{IgM}(\mathrm{RIBT})$ & \\
\hline Castile-León & 930 & 2 & 0 & 0 & 0 & 0 \\
\hline Extremadura & 163 & II & 7 & 7 & I & 0 \\
\hline Andalousia & 652 & 14 & 0 & 0 & 0 & 0 \\
\hline Basque Country & 110 & 19 & 13 & 7 & 5 & 2 \\
\hline Total & 1855 & 46 & 20 & 14 & 6 & 2 \\
\hline
\end{tabular}

\section{Sewage samples}

Forty-five sewage samples were collected at the entry of four plants for sewage treatment emplaced at the localities of Cantalejo, Coca, Palazuelos de Eresma, and Villacastín, in the province of Segovia. Sampling extended from February 2009 to December 2010. Samples were collected in sterile 500-mL polyethylene containers and kept at $4^{\circ} \mathrm{C}$ for less than eight hours before viral particles were concentrated in phosphate buffered saline solution (PBS, $\mathrm{pH} 7.3)^{22}$ and stored at $-80^{\circ} \mathrm{C}$.

\section{Laboratory tests}

Total anti-HEV was tested in human serum samples by indirect enzyme-immunoassay (EIA) (HEV Ab, Diagnostic Bioprobes Srl, Milano Italy). Performance parameters of this test were described previously. ${ }^{19}$ Samples reactive for total anti-HEV were tested separately for anti-HEV IgG and IgM by recombinant immunoblot test RIBT (recombLine HEV, Mikrogen $\mathrm{GmbH}$, Martinsried, Germany). Test validation and interpretation of results were done as specified by the manufacturer.

Serum samples from 94 pigs were tested for specific anti-HEV IgG antibodies using an in house enzyme-linked immunosorbent assay (ELISA) as described elsewhere. ${ }^{23}$ To minimize the background colour a corrected optical density (OD) was calculated (antigen-coated well OD value less uncoated well OD value). The working solution for anti-IgG conjugate was 1:50,000 (Serotec ltd., Oxford, UK). The optical density was read at $450 \mathrm{~nm}$. Control sera included in each plate were obtained from pigs identified as positive or negative as previously described. ${ }^{24}$ Samples that had an OD value equal or greater than the cut-off value ( 0.300$)$ were considered positive. ${ }^{24}$

HEV RNA was tested in human, swine and sewage samples by reverse-transcription, nested polymerase chain reaction (RT-PCR). ${ }^{1}$ RNA extraction was performed by an automated method (MagNa Pure LC, Roche, Mannheim, Germany). HEV genome fragments from ORF1 and ORF2 amplified by RT-PCR were submitted to direct sequencing, and sequences were compared by phylogenetic analysis. ${ }^{1}$

\section{Results}

\section{HEV infection among humans}

Abnormal serum aminotransferase level (ALT and/or AST $\geq 200$ UI/l) was found in samples from 1855 patients (Table 1). Seven hundred and sixty-two patients had symptoms of acute hepatitis at admission. After testing for markers of infection by hepatitis A, B and $\mathrm{C}$ viruses, and investigating potential causes of non-infectious nature, 46 patients $(2.5 \%)$ were selected for HEV testing. Reactivity for anti-HEV was found by EIA in samples from 20 patients, and was confirmed by RIBT in 14 (Table 2). Six of these 14 patients tested 
positive for anti-HEV IgM. HEV RNA was found by PCR in two of them, and both HEV strains were from genotype 3. One of these two patients tested negative for anti-HEV by RIBT, and seroconversion to anti-HEV IgM and IgG was found on follow-up. Accordingly with the criteria for interpretation of results explained above, acute HEV infection was, therefore, identified in six of the 46 suspected cases (13.4\%), and evidence of contact with HEV in the past, but unrelated to the ongoing liver alterations, was obtained in eight (17.3\%).

Five of six patients with acute HEV infection were residents of the Basque Country, and two of them referred a recent international travel. The remaining was from Extremadura and did not travel abroad. Two imported and four autochthonous cases of acute HEV infection were, therefore, found. None of the last four patients had professional contact with pigs, nor recognised a habit of consumption of raw pork meat.

\section{Prospection of HEV infection in swine livestock}

HEV RNA was detected in three of 287 swine stool samples tested (1\%) (Table 3). Positive samples were taken from piglets six to eight weeks old from a single farm (Cantalejo). HEV-3 was identified by sequencing in one sample.

Anti-HEV was found in 52 of 94 (55.3\%) swine serum samples tested. Positive samples were found in piglets from all farms, the prevalence ranging from 51.1 to $60 \%$. Piglets aged above 20 weeks displayed the highest anti-HEV prevalence (71.1\%).

\section{Testing of HEV RNA in sewage}

Forty-five sewage samples were collected and tested for HEV RNA. All samples tested negative. Amplification of the internal control was observed in all cases.

Table 2 HEV infection markers identified in samples from I 4 patients displaying anti-HEV in serum

\begin{tabular}{|c|c|c|c|c|c|}
\hline Patient & Region & Date of sampling & Anti-HEV IgG/IgM (RIBT) & HEV RNA (PCR) ORF I/ORF2 & Travel \\
\hline 1 & Basque Country & Apr-20-2009 & $+/+$ & $-/-$ & Yes \\
\hline 2 & Basque Country & Jun-12-2009 & $+/+$ & $-/-$ & No \\
\hline $3 a$ & Basque Country & Oct-26-2009 Nov-06-2009 & $\begin{array}{l}-/- \\
+/+\end{array}$ & $\begin{array}{l}+/+ \\
-1-\end{array}$ & No \\
\hline 4 & Basque Country & Dec-29-2009 & $+/+$ & $-1-$ & Yes \\
\hline 5 & Extremadura & Jul-26-20I0 & $+/+$ & $-/-$ & No \\
\hline 6 & Basque Country & Sept-04-2009 & $+/-$ & $-/-$ & No \\
\hline 7 & Basque Country & Jun-28-2010 & $+/-$ & $-/-$ & No \\
\hline 8 & Extremadura & Jul-26-20I0 & $+/-$ & $-/-$ & No \\
\hline 9 & Extremadura & Jul-26-2010 & $+/-$ & $-/-$ & No \\
\hline 10 & Extremadura & Jul-26-20I0 & $+/-$ & $-/-$ & No \\
\hline II & Extremadura & Jul-26-20I0 & $+/-$ & $-/-$ & No \\
\hline 12 & Basque Country & Apr-27-20II & $+/+$ & $+/+$ & No \\
\hline 13 & Extremadura & Sep-20-20II & $+/-$ & $-/-$ & No \\
\hline 14 & Extremadura & Sep-30-20II & $+/-$ & $-/-$ & No \\
\hline
\end{tabular}

a-Sample from October 26 was tested for HEV RNA after the next one tested positive for anti-HEV.

Table 3 Results for HEV RNA and anti-HEV obtained in samples from swine livestock from the province of Segovia

\begin{tabular}{|c|c|c|c|c|c|}
\hline \multirow{2}{*}{ Farm } & \multirow{2}{*}{ Age (Weeks) } & \multicolumn{2}{|c|}{ HEV RNA in stool } & \multicolumn{2}{|c|}{ Anti-HEV IgG in serum } \\
\hline & & Tested & Positive (\%) & Tested & Positive (\%) \\
\hline \multirow{2}{*}{ Cantalejo } & $6-8$ & 26 & $3(11.5)$ & - & - \\
\hline & $11-14$ & 54 & 0 & 24 & $14(58.3)$ \\
\hline \multirow{2}{*}{ Coca-I } & $|I-| 4$ & 31 & 0 & II & $5(45.4)$ \\
\hline & $22-23$ & 14 & 0 & 14 & $10(71.4)$ \\
\hline \multirow{2}{*}{ Coca-2 } & $11-14$ & 103 & 0 & 21 & $6(28.5)$ \\
\hline & $22-23$ & 24 & 0 & 24 & $17(70.8)$ \\
\hline \multirow[t]{2}{*}{ Coca 3} & $|I-| 4$ & 35 & 0 & - & - \\
\hline & $6-8$ & 26 & $3(I I .5)$ & - & - \\
\hline \multirow[t]{2}{*}{ Total } & $11-14$ & 223 & 0 & 56 & $25(44.6)$ \\
\hline & $22-23$ & 38 & 0 & 38 & 27 (7I.I) \\
\hline
\end{tabular}

\section{Discussion}

Prospective studies in regard to HEV infection among humans have been scarce in Spain. ${ }^{21}$ The present study was designed for approaching the role of $\mathrm{HEV}$ as an agent causing liver alterations in our country, either asymptomatic or resulting in acute hepatitis. Since viral RNA was investigated only in samples testing positive for anti$\mathrm{HEV}$, patients sampled during the window period of the infection would not have been recognised. Keeping in mind such limitations, acute HEV infection was diagnosed in six of $46(13.0 \%)$ patients displaying liver alterations of unknown etiology studied. Such yield was very close to the yield reported previously from a retrospective study where HEV was found responsible for $11.4 \%$ of 277 suspected cases studied. ${ }^{2}$

In addition to patients displaying markers specific for acute HEV infection, anti-HEV IgG was found in eight patients (17.4\%) testing negative for anti-HEV IgM and HEV RNA, who were interpreted 
as having had a prior contact with HEV unrelated with their current liver abnormalities. The prevalence of anti-HEV among adults from the Spanish general population was, in contrast, estimated $7.3 \%$ in Catalonia ${ }^{20}$ and 2.2\% in Madrid, ${ }^{19}$ which represents from less than one half to one eighth the prevalence found among the patients selected in the present study. Six of these eight patients were studied because detection of abnormal aminotransferase serum level of unexplained origin in absence of symptoms of acute hepatitis. The current concepts about the natural history of the acute HEV infection have been established after the study of patients with acute hepatitis due to HEV1 strains. Whether the asymptomatic acute infection caused by HEV-3 strains might or not originate a different viral dynamics and a different pattern of antibody response remains, therefore, open to discussion.

The selection of centres participating in the present study was done with the aim of testing the hypothesis of swine livestock as a main reservoir for transmission of HEV to humans. The hospital of Llerena represented a region of Spain (Extremadura) where swine livestock accounts among the main economic activities. Eleven patients were selected to study at that centre, and just one (9\%) could be diagnosed of acute HEV infection. In contrast, the hospital of Donostia represented a region (Basque Country) where swine livestock is scarce and is irrelevant for economy. This centre selected 19 patients to study, and three (15.8\%) were identified as suffering an acute HEV infection acquired locally. Clustering of cases of acute HEV infection in the North of Spain was already reported.$^{2}$ and has been confirmed by additional data. ${ }^{25}$ The results of the present investigation do not support, therefore, swine livestock as a main source for human HEV infections in Spain.

An aim of the present study was investigating human and swine $\mathrm{HEV}$ infection, and presence of HEV in sewage, within the limits of a rural area where swine livestock is common. After considering 930 patients with abnormal aminotransferase serum levels, just two cases could be selected for study by the regional hospital of Segovia, and both tested negative for HEV markers. In agreement with these findings, HEV RNA was not found in sewage after testing a significant number of samples, which contrasts strongly with the findings reported from certain urban areas of Spain. ${ }^{22,26}$ Although sewage is treated before being released to the environment, conventional wastewater treatment does not completely remove all viruses. ${ }^{27}$ This would explain why in some studies HEV is detected in sewage.

Results from testing anti-HEV in swine livestock showed, in contrast, that virus infection of piglets less than 22 weeks of age is a common event in the farms of the region, and the finding of HEV RNA in stool from just two of 26 piglets aged from six to eight weeks suggested that the infection takes place very early in life. Other studies performed in Spain. ${ }^{14,28,29}$ and elsewhere ${ }^{30,31}$ have drawn similar conclusions.

\section{Conclusion}

The present study suggests, in conclusion, that although the HEV infection is common among the Spanish swine livestock, pigs might not be in the origin of most autochthonous human infections in Spain. Food prepared with cured pork meat is traditionally consumed by Spaniards, but consumption of raw pork meat or pork liver is exceptional in Spain. However, acquisition of HEV by consumption of cured pork meat products has been recently reported. ${ }^{32}$ In addition to pigs, anti-HEV has been detected among bovine livestock from several countries, including Spain, ${ }^{23}$, and HEV RNA from genotype 4 has been reported from stool samples from cattle in the Chinese region of Xinjian. ${ }^{33}$ Cattle feeding are a main activity in rural areas from the Northern regions of Spain, where human HEV infections seem to cluster. Development of prospective studies involving patients with liver abnormalities and livestock other than swine from these regions is likely to provide significant data about the epidemiology of the HEV infection in Spain, as well as to focus future studies in regard to HEV transmission in Europe.

\section{Acknowledgments}

The authors wish to thank Isidoro Bustillo, Carmen García and Lucía Morago for their excellent technical assistance, as well as Dr Rosina Gironés for providing support to concentrate HEV from water. This work was supported by grant PI/080865 from the Fondo de Investigaciones Sanitarias, Spanish Ministry of Science and Innovation.

\section{Conflicts of interest}

The authors declare no conflicts of interest.

\section{Funding}

None.

\section{References}

1. Fogeda M, Avellón A, Cilla CG, et al. Imported and autochthonous Hepatitis E virus strains in Spain. J Med Virol. 2009;81(10):1743-1749.

2. Echevarría JM, Fogeda M, Avellón A. Diagnosis of acute hepatitis E by antibody and molecular testing A study on 277 suspected cases. J Clin Virol. 2011;50(1):69-71.

3. Wichmann O, Schimanski S, Koch J, et al. Phylogenetic and casecontrol study on hepatitis E virus infection in Germany. J Infect Dis. 2008;198(12):1732-1741.

4. Clemente Casares P, Rodríguez Manzano J, Gironés R. Hepatitis E virus genotype 3 and sporadically also genotype 1 circulate in the population in Spain. J Water Health. 2009;7(4):664-673.

5. Meng XJ, Lindsay DS, Sriranganathan N. Wild boars as sources for infectious diseases in livestock and humans. Philos Trans $R$ Soc Lond B Biol Sci. 2009;364:2697-2707.

6. Meng XJ. Hepatitis E virus animal reservoirs and zoonotic risk. Vet Microbiol. 2010;27(3-4):256-265.

7. Pavio N, Meng XJ, Renou C. Zoonotic hepatitis E animal reservoirs and emerging risks. Vet Res. 2010;41(6):46.

8. Van der Poel WH, Verschoor F, van der Heide R, et al. Hepatitis E viral sequences in swine related to sequences in humans. Emerg Infect Dis. 2001;7(6):970-976.

9. Herremans M, Vennema H, Bakker J, et al. Swine-like hepatitis E viruses are a cause of unexplained hepatitis in the Netherlands. J Viral Hepat. 2007;14(2):140-146.

10. Fernández Barredo S, Galiana C, García A, et al. Prevalence and genetic characterization of hepatitis $\mathrm{E}$ virus in paired samples of feces and serum from naturally infected pigs. Can J Vet Res. 2007;71(3):236-240.

11. Kaba M, Davoust B, Marie JL, et al. Frequent transmission of hepatitis E virus among piglets in farms in Southern France. $J$ Med Virol. 2009;81(10):1750-1759.

12. Rutjes SA, Lodder WJ, Bouwknegt M, et al. Increased hepatitis E virus prevalence on Dutch pig farms from 33 to $55 \%$ by using appropriate internal quality controls for RT-PCR. J Virol Methods. 2007;143(1):112_ 116. 
13. Seminati C, Mateu E, Peralta B, et al. Distribution of hepatitis E virus infection and its prevalence in Spanish farrow to finish swine herds. Vet J. 2008;175(1):130-132.

14. Casas M, Pujols J, Rosell R, et al. Retrospective serological study on hepatitis E infection in pigs from 1985 to 1997 in Spain. Vet Microbiol. 2009;135 (3-4):248-252.

15. Aggarwal R. Hepatitis E Does it cause chronic hepatitis? Hepatology. 2008;48(4):1328-1330.

16. Gérolami P, Moal V. Chronic hepatitis E with cirrhosis in a kidney transplant recipient. $N$ Engl J Med. 2008;358:859-860.

17. Haagsma EB, van den Berg AP, Porte RJ, et al. Chronic hepatitis E virus infection in liver transplant recipients. Liver Transpl. 2008;14(4):547553.

18. Kamar N, Selves J, Mansuy JM, et al. Hepatitis E virus and chronic hepatitis in organ-transplant recipients. NEngl J Med. 2008;358(8):811817.

19. Fogeda M, Avellón A, Echevarría JM. Prevalence of specific antibody to hepatitis E virus in the general population of the Community of Madrid, Spain. J Med Virol. 2012;84(1):71-74.

20. Buti M, Domínguez A, Plans P, et al. Community based seroepidemiological survey of hepatitis E virus infection in Catalonia, Spain. Clin Vaccine Immunol. 2006;13(12):1328-1332.

21. Pina S, Buti M, Cotrina M, et al. HEV identified in serum from humans with acute hepatitis and in sewage of animal origin in Spain. J Hepatol. 2000;33(5):826-833.

22. Rodríguez Manzano J, Miagostovich M, Hundesa A, et al. Analysis of the evolution in the circulation of HAV and HEV in eastern Spain by testing urban sewage samples. $J$ Water Health. 2010;8(2):346-354.

23. Peralta B, Casas M, de Deus N, et al. Anti-HEV antibodies in domestic animal species and rodents from Spain using a genotype 3-based ELISA. Vet Microbiol. 2009;28 (137):63-76.
24. Meng XJ, Purcell RH, Halbur PG, et al. A novel virus in swine is closely related to the human hepatitis E virus. Proc Natl Acad Sci U S A. 1997;94(18):9860-9865.

25. Echevarria JM, Fogeda M, Avellón A. Update of cases of acute hepatitis E confirmed by the National Centre of Microbiology (Spain, 2004 2011). Enferm Infecc Microbiol Clin. 2013;31(1):57-58.

26. Clemente Casares P, Pina S, Buti M, et al. Hepatitis E virus epidemiology in industrialized countries. Emerg Infect Dis. 2003;9(4):448-454.

27. Rusiñol M, Fernandez Cassi X, Timoneda N, et al. Evidence of viral dissemination and seasonality in a Mediterranean river catchment implications for water pollution management. J Environ Manage. 2015;15(159):58-67.

28. De Deus N, Casas M, Peralta B, et al. Hepatitis E virus infection dynamics and organic distribution in naturally infected pigs in a farrowto-finish farm. Vet Microbiol. 2008;25(132):19-28.

29. Jiménez de Oya $\mathrm{N}$, de Blas I, Blázquez AB, et al. Widespread distribution of hepatitis $\mathrm{E}$ virus in Spanish pig herds. BMC Research Notes. 2011;4:412.

30. Huang FF, Haqshenas G, Guenette DK, et al. Detection by reverse transcription-PCR and genetic characterization of field isolates of swine hepatitis E virus from pigs in different geographical regions of the United States. J Clin Microbiol. 2002;40(11):1326-1332.

31. Cooper K, Huang FF, Batista L, et al. Identification of genotype 3 hepatitis E virus (HEV) in serum and fecal samples from pigs in Thailand and Mexico, where genotype 1 and $2 \mathrm{HEV}$ strains are prevalent in the respective human populations. J Clin Microbiol. 2005;43(4):1684-1688.

32. Echevarría JM, Fogeda M, Avellón A. Epidemiology of hepatitis E virus in Spain. Enferm Infecc Microbiol Clin. 2015;33(4):281-286.

33. Hu GD, Ma X. Detection and sequences analysis of bovine hepatitis E vírus RNA in Xinjiang autonomous region. Bing Du Xue Bao. 2010;26(3):27-32. 